\section{Drugged by tobacco}

SIR - The tobacco industry continues to support research claiming that nicotine is not an addictive drug. Recently, however, 17 million Italian smokers suffered nicotine withdrawal syndrome as a consequence of an interruption of cigarette supplies during November and December 1992.

The production and distribution of tobacco in Italy was under direct government control until December when Parliament approved a bill converting the state factories into private companies. Fearing that they would lose certain benefits, the tobacco factory workers went on strike for more than 30 days, emptying the shelves of thousands of tobacconists all over the country. Long queues of smokers formed outside tobacconists when supplies arrived.

Once supplies were exhausted, people smoked whatever they could lay their hands on, including cigars and even cigarettes made from aromatic herbs and intended to help people to stop smoking. Some snatched lighted cigarettes from the lips of other smokers in the street. Many people crossed national borders or caught ferries to buy cigarettes in neighbouring countries. On international flights, duty-free cigarette supplies were soon exhausted and customs authorities enforced more severe inspections at borders and airports, a measure that aggravated the craving. Luggage from international flights was opened before customs inspection in the search for cigarettes.

As expected, there was an immediate boom in the black market. The price of a packet of tobacco rose tenfold. Social relationships were characterized by people talking about the want of cigarettes and smokers openly showed nervousness and irritability in all social environments.

This pattern of behaviour fits the definition of craving recently formulated by the United Nations International Drug Control Program-World Health Organisation (UNIDCP-WHO): "Drug craving is the desire for the previously experienced effects of a psychoactive substance. This desire can become compelling and can increase in the presence of both internal and external cues, particularly with substance availability. It is characterized by an increased likelihood of drug-seeking behaviour and, in humans, of drug-related thoughts."

The pattern of social and individual behaviour associated with nicotine withdrawal is therefore identical to the pattern of behaviour produced, for instance, during abstinence from heroin or any other drug of abuse. Indeed, the reinforcing properties of nicotine and of all other drugs abused by humans have a common neurobiological substrate, independently of their primary mechanism of action. Thus the massive nicotine abstinence syndrome in Italy provides clear evidence that cigarette smoking is addictive, and deserves extensive study for its psychosocial and sociopolitical implications.

\section{Zvani L. Rossetti}

Glan Lulgi Gessa

B.B. Brodie Department of Neuroscience, University of Cagliari,

via Porcell, 4 ,

09124 Cagliari, Italy

\section{Spanish science}

SIR - Alison Abbott's analysis (Nature 360,$502 ; 1992$ ) of the situation of Spanish science is basically correct. However, as one of the postdoctoral fellows with the privilege of having a contract after three years of training in the United States, I want to make it clear that the length of these contracts is not really three years but is limited to the duration of the scientific project to which the fellow is assigned. Thus it is possible to have contracts of one year or less, unless the grant that sustains the funding for the project is renewed. This situation clearly adds more anxiety to the already complicated adjustments of returning to Spain.

As Abbott implies, lack of development of a biotechnological industry and the general absence of participation of public or private institutions (besides CSIC) in basic research contributes to the shrinking job market. Active participation of the public network of hospitals in basic research or restrictive measures to prevent the almost systematic promotion of insiders to permanent positions in Spanish universities would certainly boost the sagging spirits of Spanish scientists.

\section{Santlago Lamas}

Universidad de Alcalá, Campus Universitario,

Carretera Madrid-Barcelona, $\mathrm{Km}$ 33,600, 28871 Alcalá de Henares (Madrid), Spain

\section{Luis Izquierdo}

SIR - Your readers will be sorry to hear of the death on 10 December 1992 of the Chilean biologist Luis Izquierdo at the age of 64 . Izquierdo was strongly opposed to the Pinochet regime in Chile (see L. Izquierdo Nature 253, 5; 1975 \& P. Cordero et al. Nature 308, 310; 1984), for which reason he was dismissed in 1981 from the post he had held since
1964 at the University of Chile.

From January 1982 to the end of March 1983 he was supported by the Chilean Society of Biology, and, thanks to national and international pressure from the scientific community, he was reinstated as professor of biology at the University of Chile in October 1983.

\section{G. Whittingham}

MRC Experimental Embryology

\& Teratology Unit,

St George's Hospital Medical School, Cranmer Terrace, London SW17 ORE, UK

\section{Barros}

Pontificia Universidad

Católica de Chile,

Santiago, Chile

\section{New DNB}

SIR - Work on a New Dictionary of National Biography has now begun, funded by a grant from the British Academy. The New $D N B$, to be published by Oxford University Press, will expand the present Dictionary of National Biography (which began publication in 1885 ) from about 37,000 to about 50,000 entries, revising or rewriting the existing entries in the process

An important part of this exercise is to discover the views of users about the present $D N B$ and what improvements they think might be made in the New $D N B$, and to enable potential contributors to offer their services and to suggest new entries.

A questionnaire has been prepared that allows the respondent to give his/her views and to sign up. Anyone interested in the $D N B$ and its future is urged to write to me at the address below to ask for one and then to fill it in.

\section{Colin Matthew}

(Editor)

New Dictionary of National Biography,

Oxford University Press,

Walton Street, Oxford OX2 6DP, UK

\section{Primo Levi}

SIR - I was commissioned in 1989 by Hutchinson to write a biography of Primo Levi, and I have now returned from six months in Italy conducting initial research. Although there is no authorized biography of Primo Levi, I do have cooperation from members of his family. If any of your readers knew Levi, I would be very grateful to hear from them. I am especially interested to see any correspondence, manuscripts or other documents relating to Levi's life, work and character. The greatest care will be taken of any such material.

lan Thomson

21 Gloucester Street,

London SW1V 2DB, UK 